\title{
Not a tragedy but a tool
}

In the latest of a monthly series in which patients and carers set the learning outcomes for readers, Alex Brett questions the helpfulness of seeing disability as a tragedy. For more information about the series, contact Rosamund Snow, patient editor, rsnow@bmj.com.

\section{Alex Brett}

The first time went a bit like this: I walked slowly and painfully into the consulting room, leaning heavily on my stick. I got myself settled. My general practitioner asked to weigh me; I slowly and carefully levered myself back up to standing, walked the six steps across the room to the scales with my stick, and then slowly and carefully propped it up and balanced myself solo. We were rapidly done; I walked back over to the chair; I sat down. "So how are you," my GP asked, "and what are you here for?"

"I'd like a referral to wheelchair services," I said.

"But that's for disabled people" he protested, in horror.

The overwhelming majority of wheelchair users can walk. I'm one of them.

It's true that wheelchairs don't mesh nicely with the wider world: there are too many heavy doors that need pulling open uphill, too many places without a dropped kerb, and too many dropped kerbs that someone's thoughtlessly parked across. That isn't what having a wheelchair is about though — rather, it means that I can now visit museums and gardens, or even just go shopping, and be able to enjoy myself, and, as the icing on the cake, be able to get out of bed the next day.

Yet over and over again the medical professionals that I interact with have treated my mobility aid like it's a tragedy. Very nearly the first thing my pain clinic consultant said to me was "we need to get you out of that wheelchair." The letter containing my autism diagnosis says that as I "come to terms" with being autistic I'll "realise" that my wheelchair use is "due to sensory hypersensitivity" and I will "become less dependent on it." This in spite of my joint hypermobility and chronic fatigue, as well as the stage IV endometriosis that's encroaching on my sciatic and genitofemoral nerves, never mind on the rest of my abdomen.

I used to be a field geologist. I've hiked several approaches to Scafell Pike, a large chunk of the Tyrol in Austria, and the Tongariro Crossing in New Zealand. Every time I'm told that getting me out of that wheelchair is "our" priority I feel like crying. It took me literally years of hard work to accept that the cartilage damage in my right knee-that no amount of physiotherapy could help—-meant that I had to stop hiking; to make my peace with the fact that getting out into the mountains unnecessarily endangered not only me and my companions but the rescue services; and to accept that I'll never overwinter in Antarctica.

This work was absolutely necessary. I poured months and years of effort into doing anything at all other than use mobility aids; it exhausted me and it made me miserable to no useful purpose.

"This is my reality: my wheelchair is not a tragedy, and I've better things to spend my energy on than trying to leave it behind. When you say your priority is to get me out of it, what you're actually telling me is that you value form over function: that you would prefer that I make my disabilities invisible, no matter the cost, than that I be comfortable and happy; and that if I don't conform - when your approach doesn't bring the improvements you think it ought, no matter how much I change my life to follow doctor's orders-you'll consider me a failure."

In 2010 I went to a concert. The venue website suggested that the entire audience would have to stand; I spent the train journey petrified that I wouldn't be able to, that I'd find it impossible to enjoy this event that I'd so looked forward to. As it turned out, there was seating, but the next day I went out and bought myself a walking stick.

I spent a large proportion of 2011 and 2012 caring for a friend who owns a wheelchair with supportive postural seating. When my friend sat on the sofa, I often sat close by in the wheelchair, and without fail after about half an hour I'd find myself thinking-wow, I'm in so much less pain, clearly that means I don't need a wheelchair and I'm faking my illnesses. It took me a while to spot the obvious logical fallacy.

"In autumn 2012 I got a chair of my own. I instantly started to get more exercise: it was suddenly possible for me to get three miles under my own power with no effects beyond feeling energised by the work I'd done; after walking the same distance I would have been laid out flat for two days. I began to be able to engage with my undergraduate lectures: I was no longer spending all my energy on sitting roughly upright and monitoring my pain levels. I went outside for the simple joy of it; I dawdled along the river and through the botanic gardens because I could. And on the days that I did walk rather than wheel, I could walk further and faster with less cost because I didn't have to push myself through it even when it used up resources that I didn't have to spare."

By all means join me in mourning the things I cannot do yet dreamt of doing; just don't ever treat my tools like they're the 


\section{The bottom line}

- It's really difficult to get to the point of seriously considering using mobility aids: if we come to you asking for a wheelchair, the best thing you can do is help us to get one

- Of course we want to live the best life that we can, but ask us what that means for us as individuals and be mindful that this might include using a wheelchair

- Please be willing to offer information about mobility aids, including wheelchairs, to patients presenting with pain and fatigue conditions that affect their quality of life. It's reassuring to know what's available, even if we don't take you up on it

problem rather than a solution. Please listen to me when I tell you how much my chair's improved my life and work with me to find more ways that we can make life better.
Cite this as: BMJ 2015;350:h906

๑ BMJ Publishing Group Ltd 2015 